\title{
Latest Achievements on Climate Change and Forest Interactions in a Polluted Environment
}

\author{
Giulia Carriero' ${ }^{1}$, Juha-Pekka Tuovinen ${ }^{2}$, Nicholas Clarke ${ }^{3}$, Giorgio Matteucci ${ }^{4}$, \\ Rainer Matyssek ${ }^{5}$, Gerhard Wieser ${ }^{6}$, Teis Norgaard Mikkelsen7, Richard Fischer, \\ Pavel Cudlin', Yusuf Serengil ${ }^{10}$, Fabio Boscaleri11, Carlo Calfapietra ${ }^{9,12}$, \\ Zhaozhong Feng13, Elena Paoletti ${ }^{*}$ \\ ${ }^{1}$ IPP-CNR, Institute for Plant Protection-National Research Council, Florence, Italy \\ ${ }^{2}$ Finnish Meteorological Institute, Helsinki, Finland \\ ${ }^{3}$ Norwegian Forest and Landscape Inst., Ås, Norway \\ ${ }^{4}$ ISAFOM-CNR Institute for Agricultural and Forestry Systems in the Mediterranean, Rende, Italy \\ ${ }^{5}$ Ecophysiology of Plants, Technische Universitat München, Freising, Germany \\ ${ }^{6}$ Federal Office and Research Centre for Forests, Innsbruck, Austria \\ ${ }^{7}$ Technical University of Denmark, Department of Chemistry \& Biochemistry Engineering, Lyngby, Denmark \\ ${ }^{8}$ Johann Heinrich von Thunen-Institute, For World Forestry, Hamburg, Germany \\ ${ }^{9}$ Global Change Research Centre, Academy of Science of the Czech Republic, Ceske Budejovice, Czech Republic \\ ${ }^{10}$ Istanbul University, Orman Fakultesi, Istanbul, Turkey \\ ${ }^{11}$ Regione Toscana via di Novoli, Florence, Italy \\ ${ }^{12}$ IBAF-CNR, Institute of Biology and Agro-Forestry, Porano, Italy \\ ${ }^{13}$ State Key Laboratory of Urban and Regional Ecology, Research Center for Eco-Environmental Sciences, \\ Chinese Academy of Sciences, Beijing, China \\ Email: carriero@ipp.cnr.it, juha-pekka.tuovinen@fmi.fi, Nicholas.clarke@skogoglandskap.no, \\ giorgio.matteucci@isafom.cs.cnr.it, matyssek@wzw.tum.de, gerhard.wieser@uibk.ac.at, \\ temi@kt.dtu.dk, richard.fischer@vti.bund.de, cudlin.p@czechglobe.cz, serengil@istanbul.edu.tr, \\ fabio.boscaleri@regione.toscana.it, carlo.calfapietra@ibaf.cnr.it, zhzhfeng201@hotmail.com, \\ calfapietra.c@czechglobe.cz, ${ }^{*}$ e.paoletti@ipp.cnr.it
}

Received 18 January 2014; revised 3 March 2014; accepted 21 March 2014

Copyright (C) 2014 by authors and Scientific Research Publishing Inc.

This work is licensed under the Creative Commons Attribution International License (CC BY).

http://creativecommons.org/licenses/by/4.0/

c) (i) Open Access

\section{Abstract}

The COST Action FP0903 “Climate Change and Forest Mitigation and Adaptation in a Polluted Environment (MAFor)" involved 29 countries and created a platform for information exchange with experts from different fields, with the following main objectives: 1) to increase understanding of

*Corresponding author. 
the state and potential of forest mitigation and adaptation to climate change in a polluted environment and 2) to reconcile process-oriented research, long-term monitoring and applied modelling at comprehensive forest research sites. In particular, MAFor translated the existing European knowledge on climate and air pollution dynamics into prospects for forest research and monitoring, with focus on the carbon, ozone, nitrogen and water budgets. The aim of this paper is to summarize scientific activities and achievements of MAFor: the creation of a meta-database for highlighting the available data and integrating the information from European forest research/monitoring networks; the development of a new concept of forest sites for research and monitoring (Supersites); the identification of the main knowledge gaps; and the definition of priorities for forest adaptation to climate change in a polluted environment. The action also increased European capacity building in this sector by organizing five conferences, granting 64 short-term scientific missions, organizing four training schools and publishing more than 100 papers.

\section{Keywords}

\section{Air Pollution, Climate Change, Forests, Supersites, COST, FP0903 Action}

\section{COST and the Action FP0903}

COST is an intergovernmental framework for European Co-operation in the field of Scientific and Technological Research, allowing the co-ordination of nationally funded research on a European level. It is the oldest and widest European intergovernmental network for cooperation in research and was founded in 1971. COST is based on different actions and each action achieves results through cooperative activities: meetings, workshops, short-term scientific missions, and training schools. The forest-related actions are grouped under the domain FPS (Forests, Their Products and Services) in the COST framework (http://www.cost.eu/domains_actions/fps). The COST Action FP0903 (Climate Change and Forest Mitigation and Adaptation in a Polluted Environment, MAFor; http://cost-fp0903.ipp.cnr.it) ran from 2009 to 2013. This action provided a platform for information exchange, analysis of the present forest-related environmental situation and elaboration of recommendations for forest adaptation and acclimation to climate change in a polluted environment, with focus on the creation of an integrated system of monitoring and research sites. The main objectives were to create a network of different institutions working on air pollution, climate change and forests in Europe, to compare monitoring data from different sources, to identify current knowledge gaps and emerging research needs, and to develop sites where integrated soil, plant and atmospheric research and monitoring can be carried out. MAFor included four interacting working groups (WGs) (Figure 1).

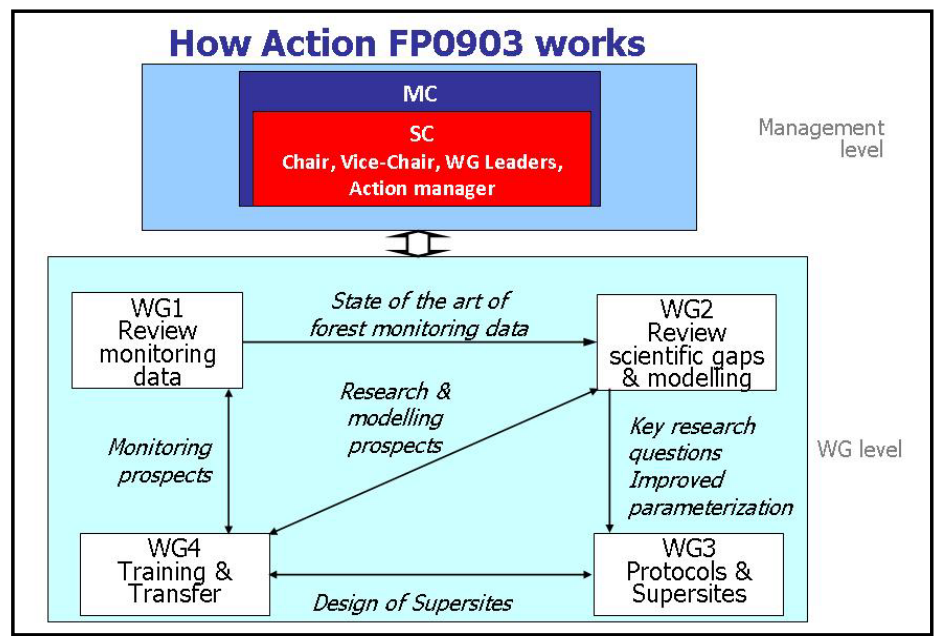

Figure 1. Summary of activities of the four working groups of COST Action FP0903. The arrows show the flow of information. 
WG 1) Availability and evaluation of monitoring data: The main assumption was that large amounts of data already made available by existing monitoring programmes and large-scale international projects working at the forest site level in Europe can be better exploited. This WG therefore aimed at facilitating knowledge of and access to existing databases and carried out a review of current sites and measurements, along with a comprehensive analysis of present datasets from European programmes (with special reference to EMEP, ICP Forests, Carbo Europe, Nitro Europe and the COST Action ES0804 on atmosphere-biosphere fluxes). The main focus was on ground-level ozone, nitrogen deposition, carbon sequestration, increased air temperature and extreme climatic events.

WG 2) Review of scientific gaps and modelling: This WG aimed to add information useful for the parameterization of models and to identify present gaps in scientific knowledge about air pollution and climate change effects on forest ecosystems. Topical limitations to the present scientific knowledge were reviewed. Present shortcomings in numerical modelling were highlighted with special reference to the dynamics of carbon and nitrogen budgets, and ozone flux. Prospects were prioritized based on their technological feasibility, novel breakthroughs and added value for the research and operational communities.

WG 3) Protocols and supersites: This WG aimed at developing a new concept of forest sites, called supersites, where integrated research and monitoring of climate and pollution impacts and feedbacks of forests to the atmosphere can be carried out, while integrating advancement in cause-effect related modelling. Specific requirements for monitoring sites and experimentation in view of ecological scenarios and instrumentation were proposed.

WG 4) Training and transfer: This WG concentrated on the logistics of the organization of common events (training schools, conferences, workshops) and the circulation of outcomes of the Action activities (website, newsletter, publications, contacts with policy makers and end users).

The aim of this paper is to summarize the main achievements obtained by each working group of MAFor and prioritize the activities for improving acclimation and adaptation of forests to climate change in a polluted environment.

\section{Main Achievements on Availability and Evaluation of Monitoring Data (WG1)}

Data from existing monitoring programmes can be used to clarify the impacts of air pollution and climate change on forest ecosystems and the feedbacks of forests to climate. For full use to be made of the available data, however, a number of questions needed to be answered related to the availability, accessibility, quality and comparability of the data. At the MAFor kick-off conference held in Rome in 2010 (Paoletti \& Tuovinen, 2011), a number of European databases, both from monitoring programmes and research projects (European Research Networks, ERNs), were identified: ICP Forests, ICP Integrated Monitoring, NitroEurope and follow-up (Eclaire), EMEP, Carbo Europe and follow-ups (IMECC, ICOS, etc.), and LTER (Clarke et al., 2011). Many of the data included in these databases are often only known to the researchers that obtained them. Published results are available as processed data in international journals, books and technical reports from programmes or projects, and they are generally protected by intellectual property rights. In principle all raw data obtained using public funding should be available to the public (OECD, 2007), even though intellectual property rights must be respected. Access to the databases can be achieved using web-based solutions, as is the case with for example EMEP data. Operation of the different ERNs often depends on the financial security of the funding organizations. Additional funding through data users might in some cases improve access, specifically when funding is insecure. A direct link between funding organization and data users would as well be of help in many cases.

Also the quality of data should be considered relative to the standard and objectives of each single project. The comparability of data from different sources, often obtained by different field and laboratory methods, needs to be tested. A cross-comparison, using for example joint protocols, ring tests and field intercomparisons (e.g. Žlindra et al., 2011), offers valuable opportunities for a better exploitation of present data including validation of models and understanding the forest response to air pollution and climate change.

A meta-database was developed with the main goal to highlight available data and integrate the information from European forest research/monitoring networks. This database is freely available at the MAFor webpage (http://cost-fp0903.ipp.cnr.it/working-groups/wg1.html). It provides important information about data on various aspects of forest ecology, surface fluxes, atmospheric physics and chemistry, and air quality (Danielewska et al., 2013a). The meta-database is divided into 13 Excel spreadsheets and includes general site information and de- 
scription of the area, flux measurements of carbon and nitrogen compounds, and-in most ERNs-basic meteorological variables. Moreover the meta-database provides information on the flux measurement system and a list of micrometeorological variables related to atmospheric turbulence. For each project, the number of measurement sites is listed. Although the focus of MAFor is on forests only, the natural ecosystem types investigated in the meta-database are forest, grassland/wetland and cropland, with description of the ecosystem in question, including leaf area index and other vegetation characteristics.

A critical analysis of the meta-database made it possible to identify current knowledge gaps and showed that: in many regions ground-level ozone is under-investigated, although it is one of the pollutants of greatest concern to forests (Serengil et al., 2011); in addition to $\mathrm{CO}_{2}$, long-term flux measurements of other greenhouse gases (GHGs) should be carried out; there is still a need of improving links between monitoring of atmospheric changes and impacts on forests because these two fundamental activities are typically carried out separately in independent ERNs; and research-oriented manipulative experiments in the forests are missing (Danielewska et al., 2013a).

The meta-database described above was created on the basis of major research and monitoring networks in Europe, but it cannot replace existing databases; it merely improves access to and coordination between the different datasets. It is important to standardize the assessment measurements, and improve access to and use of the different databases (Danielewska et al., 2013b). Understanding the interactions between natural ecosystems and the atmosphere is crucial and information about different European and international projects and programmes for various ecosystems and subjects should be integrated. The MAFor meta-database is a substantial achievement in this direction.

\section{Scientific Gaps and Modelling: Supersites and Needs (WG2)}

Of major importance to the scientific community is the identification of current knowledge gaps and emerging research areas. As an inherent element of this process, it is necessary to assess current modelling uncertainties and enhance the reliability of models, which must meet the challenge of accounting for the dynamics in carbon and nitrogen budgets and ozone flux. At the MaFor conference held in Rome, five major knowledge gaps and associated research needs were identified (Matyssek et al., 2012), related to: 1) interactions between trace gases, climate change and vegetation; 2) significance of biotic interactions in forest ecosystem response; 3) tools for mechanistic and diagnostic understanding and risk upscaling; 4) unifying modelling and empirical research; and 5) the global dimension of air pollution as part of climate change.

The recent book published by MAFor provides an integrated discussion of these issues, based on the expertise of more than 20 author teams providing book chapters, also offering perspectives for socio-economic implications and policy making (Matyssek et al., 2013a). The book consolidated evidence on separate and combined, interacting effects of elevated $\mathrm{CO}_{2}$ and $\mathrm{O}_{3}$ regimes on forest trees and tree plantations. Mostly stimulatory and inhibitory responses to elevated $\mathrm{CO}_{2}$ or $\mathrm{O}_{3}$ regimes, respectively, were found. Sensitivity to such interactions increases at intermediate tree age. However, evidence is largely lacking on stand-level processes and mature forest ecosystems, where $\mathrm{CO}_{2} / \mathrm{O}_{3}$ interactions act in concert with other abiotic and biotic stressors. This is why the development of process-based ecosystem models is hindered, and thus our ability for reliably predicting effects on forest ecosystems is still rudimentary. Crucial knowledge deficits about long-term factorial interactions are ecosystem-level productivity and water use, and their mechanistic anchoring in the net ecosystem resource exchange, in particular regarding ageing forests and deciduous or mixed versus evergreen systems. Substantial progress has been made in understanding combined $\mathrm{CO}_{2} / \mathrm{O}_{3}$ effects on biotic interrelationships as represented by arthropod-tree interactions and belowground mycorrhizal and soil microbial systems. Knowledge now exists on interactions of gaseous regimes as affecting herbivory, predation and decomposition, and on consequences for stand-level nutrient cycling, productivity and carbon storage. Limitation by $\mathrm{O}_{3}$ is at present difficult to quantitatively predict. Ecosystem-level experimentation by means of free-air gas exposure technologies is an ultimate analytical tool to answer this latter issue taking into account the high ecological system-level complexity.

Detoxification systems have been corroborated and unveiled as being essential for stress tolerance and defence, in particular regarding $\mathrm{O}_{3}$ stress (Dizengremel et al., 2013). Novel molecular tools have advanced our mechanistic understanding, revealing population-scale genetic variation, and markers have been identified for $\mathrm{O}_{3}$ tolerance (Oksanen et al., 2013). Such progress will contribute to modelling the risk of detrimental effects at the cell/leaf, whole-tree and stand levels. Grounds have been created for fostering the "gene to ecosystem" per- 
spective as a required extension of conventional systems biology, that is, through coupling tools from molecular genetics and "omics" research with approaches from experimental ecology and ecosystem analysis (Ernst, 2013).

An important observation is that in some regions the effect of climate change on atmospheric processes may offset the benefits gained from the air pollution-related emission reductions (Cieslik et al., 2013; Tuovinen et al., 2013). Tree productivity may not recover if $\mathrm{O}_{3}$ pollution decreases, given the progressive climate warming. Despite decreasing $\mathrm{SO}_{2}$ and $\mathrm{NO}_{\mathrm{x}}$ emissions, in some regions climate change will also alter ecosystem hydrology so as to cause $\mathrm{C}$ and $\mathrm{N}$ sequestration to decline. Conversely, re-acidification of soil and water is indicated to proceed as a result of enhanced soil $\mathrm{N}$ mobilization. Such evidence provides arguments for integrating climate and pollution policies to evaluate related co-benefits and trade-offs. Atmosphere-biosphere exchange processes, such as $\mathrm{O}_{3}$ deposition and emissions of biogenic volatile organic compounds (BVOCs), directly affect air quality and climate, confirming the inherent biogeochemical link between forest ecosystems and the atmosphere (Cieslik et al., 2013). Future atmospheric changes may affect the $\mathrm{O}_{3}$-forming potential of BVOCs, and warming tends to enhance such BVOC functions as membrane stabilizers and antioxidants in plants (Loreto \& Fares, 2013). However, the trade-offs between stimulatory and inhibitory effects on BVOC biosynthesis and emission are poorly understood.

Similar trade-offs have been identified in $\mathrm{N}$ deposition, as low deposition rates may stimulate tree growth, whereas at high rates above critical load thresholds, the fertilizing effect is overshadowed by a range of adverse effects. Uncertainty has been identified in reliably quantifying dry N deposition (Eugster \& Haeni, 2013).

Altered climate, nitrogen, ozone and carbon cycling affect important forest ecosystem services such as $\mathrm{C}$ sequestration, soil quality and water quality and quantity (Bytnerowicz et al., 2013). Fifty COST experts from 25 countries suggested carbon cycling in forests and its links with nutrient and water relations as the most urgent priority in upcoming forest ecosystem research (Mikkelsen et al., 2013). Land use, land-use change and forestry related carbon accounting, as well as the mechanistic basis of forest health and vitality versus functional injury and economic damage, were identified as currently the most important knowledge gaps to be tackled in the future.

Uncertainty and risks appear to increase along with the dimension and species richness of biomes, e.g. rainforests and savannahs. Although $\mathrm{O}_{3}$ is hardly monitored in rural sites, awareness has increased in South America about the $\mathrm{O}_{3}$ risks to forest ecosystems, as precursor production from land-use changes and related biomass burning outweighs, by a factor of three, the emissions from traffic and industrial sources. In addition to Europe, East Asia, India and North America, $\mathrm{O}_{3}$ is expected to create new "hot spots" in South America and South Africa, where large precursor emissions from vegetation, biomass burning and other anthropogenic sources, along with the intensity of solar radiation, foster $\mathrm{O}_{3}$ formation. The analysis showed that air pollution must be considered today as an intrinsic component of climate change and global change with its underlying socio-economic implications (Matyssek et al., 2013b).

One fundamental starting point for integrative research that covers this broad range of knowledge gaps in empirical evidence and associated modelling is the introduction of a new kind of research site in forest ecosystems called supersites (Fischer et al., 2011). These sites are intended to integrate experimentation within the soilplant-atmosphere interface and model development, and to provide research platforms for clarifying the five knowledge gaps identified at the COST FP0903 conference (see above). Matyssek et al. (2012) exemplified the capacities research supersites can develop in overcoming those gaps, and associated conceptual means were outlined by Matyssek \& Mohren (2012) in integrating experimentation and modelling towards consolidating knowledge about the combined action of air pollution and climate in forest ecosystems.

Supersites can enhance our understanding of the following topics: 1) interactions between vegetation and trace gases like $\mathrm{CO}_{2}, \mathrm{O}_{3}$ and VOCs and $\mathrm{N}$ regimes under progressive climate warming; 2) empirical clarification of stomatal conductance of tree and ecosystem level pollutant uptake and canopy-level exchange processes; 3 ) interactions between elevated regimes of $\mathrm{CO}_{2}$ and $\mathrm{O}_{3}$ in tree and ecosystem response; 4) biotic influences on ecosystem response through genotypes, ontogeny and phenology of trees; 5) abiotic and biotic impacts on C cycling and sink formation in forest ecosystems in association with water and nutrient relations; 6) mechanistic grounds for ecosystem responsiveness, comprising the molecular level of metabolic control and the biochemical and physiological process levels of metabolic activity; 7) biological markers of environmental impact across the different levels of spatio-temporal organization, for promoting tool development for differential stress diagnosis; 8) synergistic insights beyond the current state of knowledge on effects of interactions between $\mathrm{CO}_{2}, \mathrm{O}_{3}, \mathrm{~N}$ 
availability and climate on forest growth, element cycling and soil carbon sequestration; 9) new development and validation of models with data about the combined impacts of air quality and climate on forest ecosystem functioning; and 10) extension of the supersite concept and associated modelling beyond the European scale to the upcoming new air pollution "hot spots" predicted for East Asia and the Southern Hemisphere. Through this ten-point approach, an integrated global perspective on forest ecosystem functionality under conditions of climate change and intrinsically related air pollution would be established.

\section{Benefits of Supersites (WG3)}

As discussed above, Fischer et al. (2011) recommend a new approach for forest monitoring and research in Europe, based on a reasonable number of highly instrumented supersites and a larger number of intensive monitoring plots linked to these. Supersites can integrate soil science, plant physiological, and atmospheric studies within experiments specifically designed to support both the development of new models and the validation of existing ones. Supersites are to be established in a range of forest ecosystems of ecological and/or economic concern as well as major geographical relevance across Europe to determine their responses to air pollution and climate change impacts. This system needs to be built on existing infrastructures but requires increased coordination, harmonisation and a joint long-term platform for data exchange and modelling.

At the conference held in Rome in 2010, a number of transnational European networks related to forest research and monitoring were identified as potential platforms. The number of countries participating in the different networks in Europe varies among the different programmes/projects. The research networks provide important information on various aspects of forest ecology, surface fluxes, atmospheric physics, chemistry and air quality. The networks are also focused on specific topics and are interlinked and coordinated by a central institute or agency but operate through national institutions that serve as partners or national focal points. Such national focal points for different international networks often operate under different institutions, which can hamper the necessary cooperation.

Scientific use of the existing data is usually limited, because the knowledge of existing monitoring and research networks is incomplete and data availability and exchange may be difficult. Long-term data from a large number of monitoring plots are becoming important for research including model development and validation. Monitoring results potentially provide input for new research that is important for the development of monitoring methods. In addition, most networks are co-financed through temporally limited external funds and usually rely on national budgets. An important improvement of the existing forest monitoring and research infrastructures can be obtained by combining long-term experiments with ecosystem level monitoring and modelling.

What is recommended is to combine monitoring data with ecologically relevant experiments towards mechanistic forest ecosystem understanding for enhancing predictive modelling capacities and reliable risk assessment. It is also recommended to: 1) continue the analysis and compilation of information from existing long-term monitoring data sets including evaluations of impacts of air pollution and climate change on forest ecosystem services; 2) develop, test and apply a joint classification of existing sites in order to enable communication between managers of different networks; 3) establish an integrated system of monitoring and research sites covering the main European forest types; 4) build an integrated system on existing networks and data which need to be linked in order to enable harmonisation of assessments and efficient data flows; 5) encourage closer links between the communities of experimentalists, monitoring experts and modellers; 6) support and continue collaboration and contacts between existing networks and their coordinating centres on the transnational level; and 7) support collaboration on the national level, as the desired creation and joint use of sites can only be achieved through the collaboration of the national site managing institutions. The supersite concept, upon successful setup in Europe, is intended to provide a platform for extension towards a global research network, in particular comprising supersites across the Southern hemisphere.

A comprehensive discussion of the measurements to be carried out at an ideal supersite is presented in Paoletti et al. (2013). In order to estimate the $\mathrm{C}$ and $\mathrm{N}$ budgets of a forest in a changing environment, three independent methodologies are included in the measurement setup: the micrometeorological eddy covariance and gradient methods for the surface/atmosphere exchange; flux chambers; and forest inventory. Failure of each individual method alone, to either define the uncertainty (atmospheric and chamber measurements) or provide sufficient temporal resolution to investigate the processes that affect the $\mathrm{C}$ budget, suggests that these methods need to be applied in combination. The $\mathrm{O}_{3}$ budget must be coordinated with the $\mathrm{N}$ budget due to rapid chemical interactions 
between $\mathrm{O}_{3}$ and nitrogen oxides $\left(\mathrm{NO}_{\mathrm{x}}\right)$. In addition to $\mathrm{NO}_{\mathrm{x}}$, reactions with BVOCs affect the $\mathrm{O}_{3}$ fluxes above forests, while the stomatal uptake is the key determinant of plant-physiological responses (Loreto \& Fares, 2013), along with metabolic capacities of detoxification and repair (Ernst, 2013). Measuring the total $\mathrm{O}_{3}$ deposition flux, representing both stomatal and non-stomatal removal, helps understand the processes that control atmosphere-ecosystem exchange. The ultimate tool for clarification would be long-term and hectare (i.e. ecosystem) scale free-air exposure experiments with enhanced $\mathrm{O}_{3}$ and/or $\mathrm{CO}_{2}$ regimes (Matyssek et al. 2013c; King et al., 2013; Grünhage et al., 2013) in combination with micrometeorological and shoot/branch level flux measurements (Cieslik et al., 2013). Stomatal uptake rates can be derived from the measurements of water vapour exchange, based on porometer (leaf scale), cuvette (shoot/branch scale), xylem sap flow (tree scale) and micrometeorological (ecosystem scale) techniques. Such a holistic approach is needed for a realistic translation of the ongoing changes in the atmospheric environment into impacts on forest ecosystems (Paoletti et al., 2013). An integrated effort requires considerable use of resources at highly instrumented supersites, and can only be achieved by building on existing infrastructures.

\section{Main Achievements of the Dissemination Activity (WG4)}

From 2009 to 2013 dissemination activities of MAFor took place in different European countries. The first Management Committee (MC) meeting was held in Brussels (Belgium) in 2009, with participants from 21 countries. A second MC meeting was held in Antalya (Turkey) in 2010 and 19 countries were represented. The kick-off scientific conference was held in Rome (Italy) in the same year and focused on process-oriented research, long-term monitoring and applied modelling of climate change and air pollution impacts on forest ecosystems in Europe. In 2011, a conference took place in Prague (Czech Republic) and summarized the state of the art of ozone science and forest protection from ozone, suggested the most up-to-date criteria for monitoring and modelling ozone impacts on forest ecosystems and developed prospects for research and protection. In 2012, two conferences were held: in Kaunas (Lithuania) on biological reactions of forests to climate change and air pollution, and in Kahramanmaraş (Turkey) on forest-water interactions with respect to air pollution and climate change. The final conference of MAFor was held in Brussels (Belgium) in 2013. This conference addressed the priorities for forest adaptation to climate change and air pollution and summarised the outcomes of the Action. Overall, a total of 680 attendees from various continents participated in the FP0903 conferences.

A total of 64 short-term scientific missions (STSMs) were organized by MAFor. The aim of a STSM is to contribute to the scientific objectives of the COST Action and allow scientists to visit an institution or laboratory in another COST member country to foster collaboration, learn a new technique or take measurements using instruments and/or methods not available in their own country. There were STSM participants from 22 countries and they visited 17 countries. As many as $69 \%$ of STSMs were assigned to female scientists and $84 \%$ to earlystage researchers. The length of the STSM was on average 22 days. The subjects of FP0903 STSMs were well balanced among the three main subjects of the Action: monitoring (31\%), ecophysiology (39\%) and modelling (30\%). These missions were very helpful for young scientists for improving their knowledge and gaining work experience within other research institutes.

Among the many opportunities that COST provides for researchers across Europe, Training Schools (TS) give young scientists a focused and multi-disciplinary platform to access the highest level of expertise from leaders in their field. Four TSs were organized by MAFor, in collaboration with Actions ES0903 (EUROSPEC-Spectral Sampling Tools for Vegetation Biophysical Parameters and Flux Measurements in Europe) and ES0804 (ABBAAdvancing the integrated monitoring of trace gas exchange Between Biosphere and Atmosphere): in Italy, Poland (twice) and Spain. From three days to two weeks long, these TSs were attended by 115 students. The subject matters were ecophysiological and flux measurement techniques.

Overall, more than 100 papers were published as a main achievement of MAFor and other papers will be published in the near future.

\section{Priorities for Forest Adaptation to Climate Change in a Polluted Environment}

In the conclusions of the MAFor book outlined above, Matyssek et al. (2013b) stress the major areas of need for action in research: 1) getting more mechanistic; 2) fostering the global perspective; 3) promoting mechanistic modelling and risk assessment; and 4) developing supersites. These items were discussed at the final conference 
of MAFor in Brussels, and the following priorities emerged for improving forest adaptation to atmospheric changes.

1) The proposed forest research supersites (key outcome of the Action) build upon a significant number of relevant EU projects and initiatives, and suggest the integrated monitoring of water, carbon, nitrogen and ozone fluxes, to increase coordination and optimize the use of resources. The various areas for further research also needs to include $C$ stock persistence and saturation in various environmental compartments, the relationships between biodiversity and carbon sinks, the expected revision of GHG reporting in land-based activities, and forest productivity and ecosystem resilience under different scenarios of climate change and air pollution. Issues associated with the proposed research-monitoring supersites, such as policy frameworks, forest adaptation in the long-term, limitation of experiments in forestry research and regional characteristics of EU-wide forest ecosystem services, should also be considered.

2) There is an overwhelming consensus among scientists that supersites should be funded by European longterm co-financing for integrating experimentation, long-term monitoring and mechanistic modelling. The geographical distribution needs to be based on a phytoclimatic approach. The optimal number of supersites depends on funding and infrastructure design, and is driven by the research questions to be answered.

3) The European network is intended to assist in developing a global network of supersites. A global perspective is needed to harmonize approaches and derive robust results. The global dimension of air pollution as an intrinsic component of climate change is now recognised, in particular with regard to: the risks from $\mathrm{CO}_{2} / \mathrm{O}_{3}, \mathrm{~N}$ deposition and acidification in relation to warming and drought; plant-functional groups as determinants of ecosystem response; effects on biodiversity (changes in ecosystem structure, dynamics, factorial interactions); and forest burning.

4) Among the four current drivers of forest impacts, i.e. ozone, nitrogen, carbon and climate, ozone impacts and factorial interactions and feedbacks are under-investigated. Background ozone concentrations have levelled off in Europe over the past decade, but do not show significant large-scale decreases. Phytotoxic ozone dose exceeds the critical level for forests over most of Europe, indicating a risk of biomass loss. Climate change, increasing ship traffic and hemispheric transport are likely to enhance the phytotoxic ozone dose in northern Europe. Development of more advanced risk assessment methods requires multidisciplinary research focused on ozone fluxes and plant physiology.

5) Key knowledge gaps have emerged, in particular about the combined effects of climate and pollution factors on mature forests and in concert with other abiotic/biotic stressors. Research on soil biological and physicochemical processes and on tree species competition (including belowground) is recommended. Ecosystem-atmosphere BVOC/ $/ O_{3}$ interactions are recognized as crucial in terms of mitigating versus amplifying $\mathrm{O}_{3}$ impacts and in concert with climate change-driven ecosystem perturbations. There is a lack of systemic understanding that is a substantial impediment to modelling and risk assessment. There is an increasing need for linking "omics" sciences with ecophysiological research under multi-factorial, long-term, large-scale and ecosystem-level perspectives. Technological tools are now available for employing stand-level free-air gas exposure methodologies to cope with this demand.

6) Networks, sites and institutions that enable open and wide use of infrastructures and data will be successful in the long run. More use could and should be made of the large amounts of data to be found in existing longterm databases. The new COST FP0903 meta-database provides information on what data is available and where. Access to existing data should be further improved, preferably using web-based solutions. These should in principle be publicly available, as long as intellectual property rights and data security are respected. Use of proper QA/QC procedures is essential and should be mandatory. Full harmonization is hard to achieve, but comparability can to a large extent be achieved by using the same protocols, methodological intercomparisons and ring tests.

7) The final conference of MAFor coincided with the transition from the 7th EU research framework programme to Horizon 2020. There are significant changes compared to the previous framework programme, which aim at coupling research to innovation and markets, focusing on societal challenges, simplifying access for universities and companies in EU countries and beyond, assuring coherence with other EU actions (e.g. EU 2020 Strategy, Bioeconomy Strategy) and national and regional initiatives (e.g. Smart Specialisation Strategies). Nevertheless, the EU research will continue in the form of research and innovation actions and coordination and support activities, such as ERA-NET (ex-post coordination between national research programmes), Joint Pro- 
gramming Initiatives-JPI (ex-ante coordination between member states for developing research agenda), or research infrastructure projects.

8) The above mentioned final conference in Brussels also coincided with the definition of a position paper by the LEGS (Life, Environmental and Geoscience) Committee of Science Europe, which is a new association of the European Research Funding Organisation and Research Performing Organisations. The position paper to be released at the beginning of 2014 clearly mentions tropospheric ozone as a major research area to focus on, both in the area of atmospheric chemistry and in relation to the interactions (effects and mitigation) with terrestrial ecosystems.

9) Monitoring, empirical research and modelling (i.e. the three activities proposed to be integrated in the forest research supersites) are interrelated foremost due to the general need of accurate and consistent time series on forest data, as emphasized also by the recently launched Commission Communication on a New EU Forest Strategy (September 2013 http://ec.europa.eu/agriculture/forest/strategy/communication_en.pdf). A FP0903 follow-up proposal should consider the relevant legal frameworks and member state initiatives, as well as the public debate in relevant frameworks at the EU level, such as the Standing Committee on Agricultural ResearchSCAR. In addition to this, the integration of past and recent monitoring systems may benefit from further progress on cross-cutting technical issues, which are intrinsic to all monitoring and reporting systems, such as good practice guidance, quality assurance and quality control.

\section{Conclusions}

The state of knowledge evaluated so far provides ample arguments for integrating experimentation, long-term monitoring and modelling so as to provide meaningful science-based management guidelines and certification systems. An important improvement of the existing forest monitoring and research infrastructures can be obtained by combining long-term experiments with ecosystem level monitoring and with modelling. To that end, the establishment of the supersite concept is recommended. This means that independent funding mechanisms for the infrastructures and for data evaluation as well as evaluation of the legal framework are required.

It will be important to cross-compare data from different databases in order to develop advanced exploitation of present data, including validation and new development of models and understanding of real-world forest responses to air pollution and climate change. There is still a need of improving links between monitoring of atmospheric changes and impacts on forests because these two fundamental activities are carried out separately in independent ERNs.

The creation of a transnational system of supersites for forest monitoring and research can only be achieved if scientists from different disciplines and managers from different existing networks are involved. Three demands have to be met: 1) unifying the scientific communities of experimentalists, monitoring experts and modellers to work on the same sites in joint interdisciplinary research programmes; 2) designing monitoring and research to analyse the unity of process interaction between vegetation, atmosphere and soil; 3) establishing networks of supersites across continents, that is, within and between hemispheres, through global harmonization of research programmes.

Supersites have the potential to fill the gaps and provide scientifically sound knowledge for forest protection and adaptive management in a changing world, but this requires coordination, harmonization and a joint longterm platform for data exchange and modelling. The aim is to develop and validate large-scale and long-term models, in order to enable reliable risk assessment and provide prerequisites for sound policy development. Key topics for consolidating process-based knowledge are ecosystem-level carbon sequestration and storage, soil chemistry and water budgets, with major emphasis on mechanisms of soil-vegetation-atmosphere $\mathrm{CO}_{2}$ exchange, BVOC and aerosol turnover, $\mathrm{O}_{3}$ formation and uptake, and $\mathrm{N}$ deposition as related to woody-plant and ecosystem performance. As demonstrated by MAFor, science-based approaches for addressing future risks and challenges to forests require close collaboration among the communities operating monitoring and research networks as well as experts in process and large-scale modelling.

\section{Acknowledgements}

Support by the COST Action FP0903 "Climate change and forest mitigation and adaptation in the polluted environment” and by the COST officers Melae Langbein and Cassia Azevedo is greatly acknowledged. We wish 
to thank all scientists and experts who contributed to the MAFor activities, and the Grant Holder Clementina Falco for her extraordinary support with the administrative issues. We also acknowledge Doru-Leonard Irimie (European Commission, DG Research \& Innovation, F3: Agri-Food Chain) for his contribution to the final conference output.

\section{References}

Bytnerowicz, A., Fenn, M., McNulty, S., Yuan, F., Pourmokhtarian, A., Driscoll, C., \& Meixner, T. (2013). Interactive Effects of Air Pollution and Climate Change on Forest Ecosystems in the United States-Current Understanding and Future Scenarios. In: R. Matyssek, N. Clarke, P. Cudlin, T. N. Mikkelsen, J.-P. Tuovinen G. Wieser, \& E. Paoletti (Eds.), Climate Change, Air Pollution and Global Challenges: Knowledge, Understanding and Perspectives from Forest Research, Elsevier Physical Sciences Series “Developments in Environmental Science” 13, 333-363.

Cieslik, S., Tuovinen, J.-P., Baumgarten, M., Matyssek, R., Brito, P., \& Wieser, G. (2013). Gaseous Exchange between forests and the Atmosphere. In: R. Matyssek, N. Clarke, P. Cudlin, T. N. Mikkelsen, J.-P. Tuovinen G. Wieser, \& E. Paoletti (Eds.), Climate Change, Air Pollution and Global Challenges: Knowledge, Understanding and Perspectives from Forest Research, Elsevier Physical Sciences Series “Developments in Environmental Science” 13, 19-36.

Clarke, N., Fischer, R., de Vries, W., Lundin, L., Papale, D., Vesala, T., Merilä, P., Matteucci, G., Mirtl, M., Simpson, D., \& Paoletti, E. (2011). Availability, Accessibility, Quality and Comparability of Monitoring Data for European Forests for Use in Air Pollution and Climate Change Science. iForest-Biogeosciences and Forestry, 4, 162-166.

http://dx.doi.org/10.3832/ifor0582-004

Danielewska, A., Clarke, N., Olejnik, J., Hansen, K., de Vries, W., Lundin, L., Tuovinen, J. P., Fischer, R., Urbaniak, M., \& Paoletti, E. (2013a). A Meta-Database Comparison from Various European Research Networks Dedicated to Forest Sites. iForest-Biogeosciences and Forestry, 6, 1-9.

Danielewska, A., Paoletti, E., Clarke, N., Olejnik, J., Urbaniak, M., Baran, M., Siedlecki, P., Hansen, K., Lundin, L., de Vries, W., Mikkelsen, T. N., Dillen, S., \& Fischer, R. (2013b). Towards Integration of Research and Monitoring at Forest Ecosystems in Europe. Forest Systems, 22, 535-545.

Dizengremel, P., Jolivet, Y., Tuzet, A., Ranieri, A., \& Le Thiec, D. (2013). Integrative Phytotoxic Ozone Dose Assessment in Leaves in View of Risk Modelling for Forest Ecosystems. In: R. Matyssek, N. Clarke, P. Cudlin, T. N. Mikkelsen, J.-P. Tuovinen G. Wieser, \& E. Paoletti (Eds.), Climate Change, Air Pollution and Global Challenges: Knowledge, Understanding and Perspectives from Forest Research, Elsevier Physical Sciences Series "Developments in Environmental Science” 13, 267-283.

Ernst, D. (2013). Integrated Studies on Abiotic Stress Defence in Trees: The Case of Ozone. In: R. Matyssek, N. Clarke, P. Cudlin, T. N. Mikkelsen, J.-P. Tuovinen G. Wieser, \& E. Paoletti (Eds.), Climate Change, Air Pollution and Global Challenges: Knowledge, Understanding and Perspectives from Forest Research, Elsevier Physical Sciences Series "Developments in Environmental Science” 13, 289-301.

Eugster, W., \& Haeni, M. (2013) Nutrients or pollutants? Nitrogen Deposition to European forests. In: R. Matyssek, N. Clarke, P. Cudlin, T. N. Mikkelsen, J.-P. Tuovinen G. Wieser, \& E. Paoletti (Eds.), Climate Change, Air Pollution and Global Challenges: Knowledge, Understanding and Perspectives from Forest Research, Elsevier Physical Sciences Series "Developments in Environmental Science” 13, 37-56.

Fischer, R., Aas, W., De Vries, W., Clarke, N., Cudlin, P., Leaver, D., Lundin, L., Matteucci, G., Matyssek, R., Mikkelsen, T. N., Mirtl, M., Öztürk, Y., Papale, D., Potocic, N., Simpson, D., Tuovinen, L.-P., Vesala, T., Wieser, G., \& Paoletti, E. (2011). Towards a Transnational System of Supersites for Forest Monitoring and Research in Europe-An Overview on Present State and Future Recommendations. iForest-Biogeosciences and Forestry, 4, 167-171. http://dx.doi.org/10.3832/ifor0584-004

Grünhage, L., Matyssek, R., Wieser, G., Häberle, K. H., Leuchner, M., Menzel, A., Dieler, J., Pretzsch, H., Grimmeisen, W., Zimmermann, L., Raspe, S., \& Schröder, M. (2013). Flux-Based Ozone Risk Assessment for Adult Beech and Spruce Forests. In: R. Matyssek, N. Clarke, P. Cudlin, T. N. Mikkelsen, J.-P. Tuovinen G. Wieser, \& E. Paoletti (Eds.), Climate Change, Air Pollution and Global Challenges: Knowledge, Understanding and Perspectives from Forest Research, Elsevier Physical Sciences Series “Developments in Environmental Science” 13, 251-263.

King, J., Liu, L., \& Aspinwall, M. (2013). Forest Ecosystem Response to Interacting Elevated Atmospheric $\mathrm{CO}_{2}$ and Tropospheric $\mathrm{O}_{3}$ : A Synthesis of Experimental Evidence. In: R. Matyssek, N. Clarke, P. Cudlin, T. N. Mikkelsen, J.-P. Tuovinen G. Wieser, \& E. Paoletti (Eds.), Climate Change, Air Pollution and Global Challenges: Knowledge, Understanding and Perspectives from Forest Research, Elsevier Physical Sciences Series "Developments in Environmental Science” 13, 179-203.

Loreto, F., \& Fares, S. (2013). Biogenic Volatile Organic Compounds and Their Impacts on Biosphere-Atmosphere Interactions. In: R. Matyssek, N. Clarke, P. Cudlin, T. N. Mikkelsen, J.-P. Tuovinen G. Wieser, \& E. Paoletti (Eds.), Climate Change, Air Pollution and Global Challenges: Knowledge, Understanding and Perspectives from Forest Research, Else- 
vier Physical Sciences Series “Developments in Environmental Science” 13, 57-68.

Matyssek, R., \& Mohren, J. (2012) Special Topic: Integrating, Modeling and Experimentation. Trees, 26, 1679-1682. http://dx.doi.org/10.1007/s00468-012-0778-4

Matyssek, R., Clarke, N., Cudlin, P., Mikkelsen, T. N., Tuovinen, J.-P., Wieser, G., \& Paoletti, E. (2013a). Climate Change, Air Pollution and Global Challenges: Understanding and Perspectives from Forest Research. Elsevier Physical Sciences Series “Developments in Environmental Science”, 13, 622.

Matyssek, R, Knoke, T, Clarke, N, Cudlin, P, Mikkelsen, T. N., Tuovinen, J.-P., Wieser, G, \& Paoletti, E. (2013b). Conclusions and Perspectives. In: R. Matyssek, N. Clarke, P. Cudlin, T. N. Mikkelsen, J.-P. Tuovinen G. Wieser, \& E. Paoletti (Eds.), Climate Change, Air Pollution and Global Challenges: Knowledge, Understanding and Perspectives from Forest Research, Elsevier Physical Sciences Series “Developments in Environmental Science” 13, 591-607.

Matyssek, R., Wieser, G., Calfapietra, C., de Vries, W., Dizengremel, P., Ernst, D., Jolivet, Y., Mikkelsen, T.N., Mohren, G. M. J., Le Thiec, D., Tuovinen, J. P., Weatherall, A., \& Paoletti (2012). Forests under Climate Change and Air Pollution: Gaps in Understanding and Future Directions for Research. Environmental Pollution, 160, 57-65. http://dx.doi.org/10.1016/j.envpol.2011.07.007

Matyssek, R., Wieser, G., Fleischmann, F., \& Grünhage, L. (2013c). Ozone Research, Quo Vadis? Lessons from the Free-Air Canopy Fumigation Experiment at Kranzberg Forest. In: R. Matyssek, N. Clarke, P. Cudlin, T. N. Mikkelsen, J.-P. Tuovinen G. Wieser, \& E. Paoletti (Eds.), Climate Change, Air Pollution and Global Challenges: Knowledge, Understanding and Perspectives from Forest Research, Elsevier Physical Sciences Series "Developments in Environmental Science" 13, 103-129.

Mikkelsen, T. N., Clarke, N., Danielewska, A., \& Fischer, R. (2013). Towards Supersites in Forest Ecosystem Monitoring and Research. In: R. Matyssek, N. Clarke, P. Cudlin, T. N. Mikkelsen, J.-P. Tuovinen G. Wieser, \& E. Paoletti (Eds.), Climate Change, Air Pollution and Global Challenges: Knowledge, Understanding and Perspectives from Forest Research, Elsevier Physical Sciences Series “Developments in Environmental Science” 13, 475-493.

OECD (2007). Principles and Guidelines for Access the Research Data from Public Funding.

Oksanen, E., Keski-Saari, S., Kontunen-Soppela, S., \& Keinänen, M. (2013). Metabolomics and Transcriptomics Increase Our Understanding about Defence Responses and Genotypic Differences of Northern Deciduous Trees to Elevating Ozone, $\mathrm{CO}_{2}$ and Climate Warming. In: R. Matyssek, N. Clarke, P. Cudlin, T. N. Mikkelsen, J.-P. Tuovinen G. Wieser, \& E. Paoletti (Eds.), Climate Change, Air Pollution and Global Challenges: Knowledge, Understanding and Perspectives from Forest Research, Elsevier Physical Sciences Series “Developments in Environmental Science” 13, 309-326.

Paoletti, E., de Vries, W, Mikkelsen, T. N., Ibrom, A., Larsen, K. S., Tuovinen, J. P., Serengil, Y., Yurtseven, I., Wieser, G., \& Matyssek, R. (2013). Key Indicators of Air Pollution and Climate Change Impacts at Forests Supersites. In: R. Matyssek, N. Clarke, P. Cudlin, T. N. Mikkelsen, J.-P. Tuovinen G. Wieser, \& E. Paoletti (Eds.), Climate Change, Air Pollution and Global Challenges: Understanding and Perspectives from Forest Research, Elsevier Physical Sciences Series "Developments in Environmental Science” 13, 497-520.

Paoletti, E., \& Tuovinen, J.-P. (2011). COST Action FP0903: Research, Monitoring and Modeling in the Study of Climate Change and Air Pollution Impacts on Forest Ecosystems. iForest-Biogeosciences and Forestry, 4, 160-161. http://dx.doi.org/10.3832/ifor0583-004

Serengil, Y., Augustaitis, A., Bytnerowicz, A., Grulke, N., Kozovitz, A. R., Matyssek, R., Müller-Starck, G., Schaub, M., Wieser, G., Coskun, A. A., \& Paoletti, E. (2011). Adaptation of Forest Ecosystems to Air Pollution and Climate Change: A Global Assessment on Research Priorities. iForest-Biogeosciences and Forestry, 4, 44-48. Http://Dx.Doi.Org/10.3832/Ifor0566-004

Tuovinen, J.-P., Hakola, H., Karlsson, P. E., \& Simpson, D. (2013) Air Pollution Risks to Northern European Forests. In: R. Matyssek, N. Clarke, P. Cudlin, T. N. Mikkelsen, J.-P. Tuovinen G. Wieser, \& E. Paoletti (Eds.), Climate Change, Air Pollution and Global Challenges: Knowledge, Understanding and Perspectives from Forest Research, Elsevier Physical Sciences Series "Developments in Environmental Science” 13, 77-99.

Žlindra, D., Eler, K., Clarke, N., \& Simončič, P. (2011). Towards Harmonization of Forest Deposition Collectors-Case Study of Comparing Collector Designs. iForest-Biogeosciences and Forestry, 4, 218-225.

http://dx.doi.org/10.3832/ifor0586-004 